\title{
The basis of thermal melanism in the ladybird Adalia bipunctata: Differences in reflectance and thermal properties between the morphs
}

\author{
Paul M. Brakefield ${ }^{1}$ and P. G. Willmer ${ }^{2}$
}

\author{
${ }^{1}$ Department of Biological Sciences (W.S.L.), \\ University of Exeter, Perry Road, Exeter, EX4 4QG. \\ ${ }^{2}$ Department of Zoology, University of Oxford, South \\ Parks Road, Oxford, OX1 3PS.
}

The thermal properties of the red non-melanic and black melanic morphs of Adalia bipunctata were examined in the laboratory. Non-melanics have a higher cuticular reflectance than melanics. Under illumination similar to bright sunlight the temperature excess over ambient air ( $T$. ex) gained by melanics is, on average, $2 \cdot 1^{\circ} \mathrm{C}$ larger than that of non-melanics. Initial rates of temperature change during heating and cooling are nearly 50 per cent faster for melanics. $T$. ex increases with weight in each morph class and is, on average, larger for females as these are larger. The larger melanics may have a higher risk of overheating than other Adalia in conditions of prolonged sunshine and very high ambient air temperatures. The results are discussed in relation to consequences of thermal melanism in natural populations and to the contribution of colour and size to insect heat budgets.

\section{INTRODUCTION}

Geographical variation in the frequency of the melanic, and red non-melanic forms of the twospot ladybird beetle Adalia bipunctata (L.) (Coleoptera: Coccinellidae) has been extensively studied by ecological geneticists (e.g., Muggleton, 1978; Brakefield, 1984a). The polymorphism is controlled by a number of alleles at a single gene locus, with melanics dominant to non-melanics (Lus, 1928, 1932). Some earlier workers described a correlation between sites or regions of industrialisation and melanic frequency indicative of industrial melanism (Creed, 1966, 1971 a, 1974; Lees et al., 1973). Furthermore, declines in melanic frequency have been recorded at a number of English sites following a reduction in smoke pollution (Creed, 1971b; Bishop et al., 1978). The species is warningly-coloured and distasteful to at least some predators (Frazer and Rothschild, 1960; Pasteels et al., 1973; Muggleton, 1978; Brakefield, 1984b). Such observations led Creed (1971 $a$ ) to suggest that some unidentified component of the polluted atmosphere was less toxic to melanics than non-melanics. In contrast, Lusis (1961) has suggested that sunshine level is the principal factor determining melanic frequency. The associated theory of thermal melanism proposes that melanics are favoured in regions of low sunshine because more rapid heating rates and higher body temperatures are attained under insolation. Negative correlations between sunshine level and melanic frequency have been found in Britain (Benham et al., 1974; Muggleton et al., 1975) and The Netherlands (Brakefield, 1984a). The correlations are strongest during periods of adult activity. Evidence for some predictable effects of thermal melanism on the timing and intensity of adult reproductive activity and the dynamics of the polymorphism in natural populations has been obtained by Brakefield $(1984 b, c)$. It has been suggested that the apparent relationship between industrialisation and melanic frequency can be accounted for through the effects of particulate air pollution on sunshine levels (Muggleton et al., 1975).

The theory of thermal melanism in A. bipunctata rests on there being a relationship between the dorsal coloration of the morph classes and their absorption of solar radiation, but this has not been adequately demonstrated. Benham et al., (1974) found some evidence of an effect of differential absorption on activity. Thus chilled melanic A. bipunctata when placed under a tungsten lamp at temperatures of $5^{\circ} \mathrm{C}$ and $7.5^{\circ} \mathrm{C}$ were more active 
over a 12 min period than non-melanics. However, sample sizes are not given and the type of confidence limit which is presented is not specified (relevant at $7-5^{\circ} \mathrm{C}$ ). Muggleton et al., (1975) present a figure which indicates that the mean body temperature reached by five melanics illuminated by a tungsten lamp was about $1{ }^{\circ} \mathrm{C}$ higher than for five non-melanics. No information on differences between individuals is given. None of these experiments used beetles which were standardised for size (J. Muggleton, personal communication). This presents perhaps the most critical difficulty in interpreting their results. A. bipunctata exhibits a fivefold range in dry weight and males are smaller than females (Brakefield, 1984a). Body size has a substantial influence on the thermal properties of insects and comparisons between species suggest that its influence is considerably greater than that of colour (e.g., Digby, 1955; Willmer and Unwin, 1981). Hence use in the experiments of melanics and non-melanics differing in size could have accounted for differences in body temperature, or for misinterpretation of their magnitude and importance.

We report here the results of experiments which confirm the basis of thermal melanism in A. bipunctata. They were made possible by recent advances in the measurement of the cuticular reflectance and body temperature of insects (Willmer and Unwin, 1981) and by studies of the relationships of such parameters to insect activity (Willmer, 1982a, $b$, 1983).

\section{MATERIALS AND METHODS}

Samples of hibernating $A$. bipunctata were collected in December 1983 at Utrecht E. and De Uithof in The Netherlands (see Brakefield, 1984a). Beetles were obtained from the range of overwintering habitats (Brakefield, 1984d). They were kept outdoors for five to six weeks prior to the experiments. Hibernating beetles were used because they are in a more homogeneous physiological state than those that could be collected in the period of adult activity. The sample included specimens of the non-melanic typica morph, with two black spots, and of the melanic morphs, quadrimaculata and sexpustulata, with four and six red marks respectively. The phenotype of each morph is rather variable. These three morphs predominate in most populations of the species in western Europe.

The cuticular reflectance of beetles, freshlykilled with ethyl acetate, was determined using a "reflectometer" designed and described by Willmer and Unwin (1981). It uses a beam of light which has similar characteristics to northern European sunlight.

Rates of heating and cooling, and temperature excesses were recorded with a Portec PI-8913 digital thermometer unit, using type $\mathrm{K}$ (chromel/alomel) thermocouples $(0 \cdot 2 \mathrm{~mm}$ gauge wires). The meter was also linked to a two-channel Washington pen recorder to provide permanent records. Thermocouples were glued to the beetle's thoracic sternites using a fine coating of thermally conducting glue. The freshly-killed beetles were placed $7.5 \mathrm{~cm}$ below a 60 watt tungsten lamp and the resulting incident radiation was measured using a thermopile solarimeter (Unwin, 1980). Any error introduced by this procedure compared to one using thermocouples inserted into flight musculature will be the same for each morph class.

Weights of beetles were measured with a Kanicon balance to an accuracy of $0.1 \mathrm{mg}$. Temperature changes in several weight-matched pairs or trios of melanics and non-melanics were then recorded, in a standard sequence for each beetle of (1) stable body temperature without illumination, (2) heating under illumination to an equilibrium body temperature and (3) cooling to a stable body temperature without illumination. The groups of beetles were interspersed with control sequences using bare thermocouples to obtain corresponding temperature traces for ambient air. The sex of the beetles was determined later by dissection.

\section{RESULTS}

\section{Cuticular reflectance}

The values for reflectance given in Table 1 indicate that non-melanic $A$. bipunctata absorb less of the incoming radiation than melanics. The minimum and the maximum measurements for melanics are significantly lower than those for non-melanics (Mann-Whitney test statistic: $U=139.5$ and 131.5 respectively, with $P<0.001$ for each). There is no difference in weight between the test beetles of each morph class (Table 1). The weight variation covered the range characteristic of the species (Brakefield, 1984a).

Table 1 shows that measurements of reflectance for individual $A$. bipunctata varied widely. This variation is a consequence of the small diameter $(0.15 \mathrm{~mm})$ of the light beam of the reflectometer. The beetles were moved around to intercept this beam at different points on their dorsal surface. 
Table 1 Mean and range of minimum and maximum reffectance values $(r)$ for non-melanic and melanic Adalia bipunctata. Mean dry weights with 95 per cent confidence limits are given

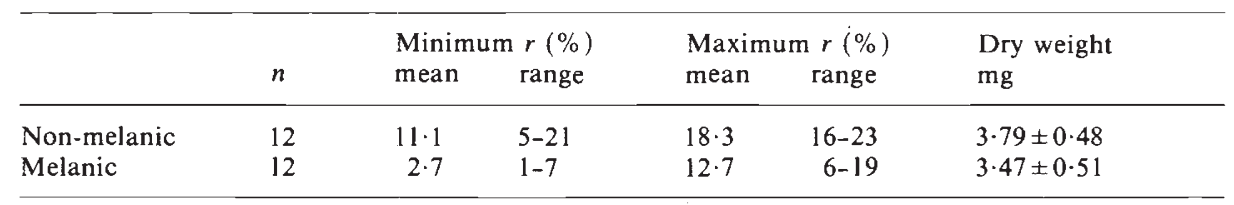

The beam is of similar cross section to the area of the largest red marks of melanics and it is not much larger than the largest black spots of non-melanics. Therefore the maxima for melanics largely describe the reflectance of the red marks whilst the minima for non-melanics are strongly influenced by the black spots. Overall values for the dorsal reflectance are then likely to range from about 3-9 per cent for melanics and 15-22 per cent for nonmelanics.

\section{Temperature changes of illuminated beetles}

Fig. 1 shows three examples of the temperature changes recorded for weight-matched pairs of nonmelanic and melanic $A$. bipunctata. In each case the melanic specimen reaches a higher temperature

a) Mean wgt. $9 \cdot 15 \mathrm{mg}$

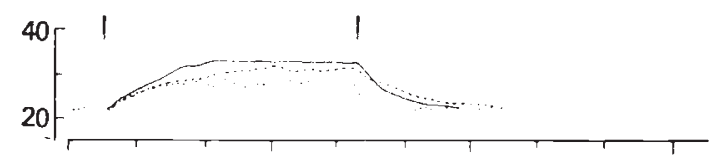

b) $10.05 \mathrm{mg}$

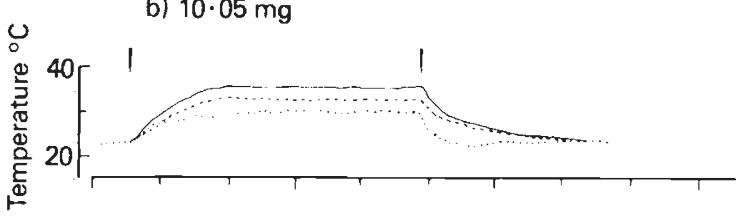

c) $13 \cdot 85 \mathrm{mg}$

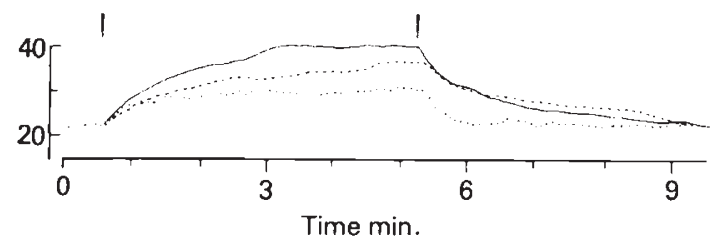

Figure 1 Ventral surface temperature versus time for three weight-matched pairs of non-melanic (- . .) and melanic (—) Adalia bipunctata (ambient air, …). Arrows indicate the start and finish of the period of illumination (radiation strength $810-860 \mathrm{Watts}^{-2}$ ). The lengths of the periods of equilibrium temperatures shown have been adjusted to standardise the period of illumination. excess over ambient air ( $T$.ex) than the nonmelanic. Similarly the initial rates of heating and cooling are faster for the melanics. Details of the temperature records for each beetle are given in Table 2. The times $\left(T . \frac{1}{2}\right)$ to reach half of the total temperature change ( $T$. chge) during heating were not significantly different from the corresponding times during cooling $(U=249 \cdot 0)$. The averages of these half-times are included in Table 2 together with the initial rates of temperature change $\mathrm{K}$ as given by $\frac{1}{2}\left(T\right.$. chge)/T. $\frac{1}{2}$. The radiation measured in periods of illumination ranged from 810 860 watts $\mathrm{m}^{-2}$ which is similar to bright midsummer sunshine at latitude $50^{\circ} \mathrm{N}$.

Fig. 1 suggests that $T$. ex is greater for the larger beetles. It is plotted against weight in Fig. 2. Each

Table 2 Thermal characteristics, weight and sex of freshlykilled individuals of the non-melanic typica (typ.) and melanic quadrimaculata (quad.) and sexpustulata (sexp.) morphs of Adalia bipunctata. The temperature excess reached in bright illumination, and the average half-time of temperature changes during heating and cooling, are given together with the initial rate of temperature change $\mathrm{K}$ (see text)

\begin{tabular}{|c|c|c|c|c|c|}
\hline Morph & Sex & $\begin{array}{l}\text { Fresh } \\
\text { weight } \\
\text { mg }\end{array}$ & $\begin{array}{l}\text { Temp. } \\
\text { excess } \\
{ }^{\circ} \mathrm{C}\end{array}$ & $\begin{array}{l}\text { Mean } \\
\text { half-time } \\
\mathrm{s}\end{array}$ & $\begin{array}{l}\text { Rate K } \\
{ }^{\circ} \mathrm{C} / \mathrm{s}\end{array}$ \\
\hline typ. & fem. & $6 \cdot 5$ & 0.0 & 27 & 0.135 \\
\hline typ. & male & $8 \cdot 4$ & $1 \cdot 1$ & 29 & 0.125 \\
\hline typ. & male & $9 \cdot 2$ & $2 \cdot 7$ & 39 & $0 \cdot 121$ \\
\hline typ. & male & $10 \cdot 0$ & 2.9 & 34 & $0 \cdot 152$ \\
\hline typ. & male & $10 \cdot 8$ & $4 \cdot 0$ & 36 & $0 \cdot 128$ \\
\hline typ. & fem. & $11 \cdot 5$ & 5.4 & 35 & $0 \cdot 152$ \\
\hline typ. & fem. & $12 \cdot 0$ & $5 \cdot 9$ & 50 & $0 \cdot 165$ \\
\hline typ. & fem. & $13 \cdot 1$ & $5 \cdot 3$ & 45 & 0.135 \\
\hline typ. & fem. & 13.9 & $7 \cdot 3$ & 58 & $0 \cdot 124$ \\
\hline quad. & male & $8 \cdot 4$ & $3 \cdot 5$ & 29 & $0 \cdot 168$ \\
\hline quad. & fem. & $8 \cdot 6$ & $3 \cdot 7$ & 27 & $0 \cdot 197$ \\
\hline quad. & male & $10 \cdot 1$ & $5 \cdot 3$ & 26 & 0.239 \\
\hline quad. & fem. & $10 \cdot 4$ & $4 \cdot 8$ & 25 & $0 \cdot 198$ \\
\hline quad. & fem. & $11 \cdot 0$ & $8 \cdot 5$ & 32 & $0 \cdot 220$ \\
\hline quad. & male & $11 \cdot 7$ & $7 \cdot 5$ & 47 & $0 \cdot 191$ \\
\hline quad. & fem. & 13.1 & $7 \cdot 3$ & 26 & 0.269 \\
\hline quad. & fem. & 13.8 & $10 \cdot 2$ & 40 & 0.215 \\
\hline sexp. & male & $8 \cdot 6$ & $4 \cdot 1$ & 32 & $0 \cdot 169$ \\
\hline sexp. & male & $9 \cdot 1$ & $3 \cdot 7$ & 29 & 0.187 \\
\hline sexp. & male & $10 \cdot 8$ & $5 \cdot 9$ & 34 & 0.192 \\
\hline sexp. & fem. & 13.6 & $10 \cdot 0$ & 48 & $0 \cdot 176$ \\
\hline
\end{tabular}




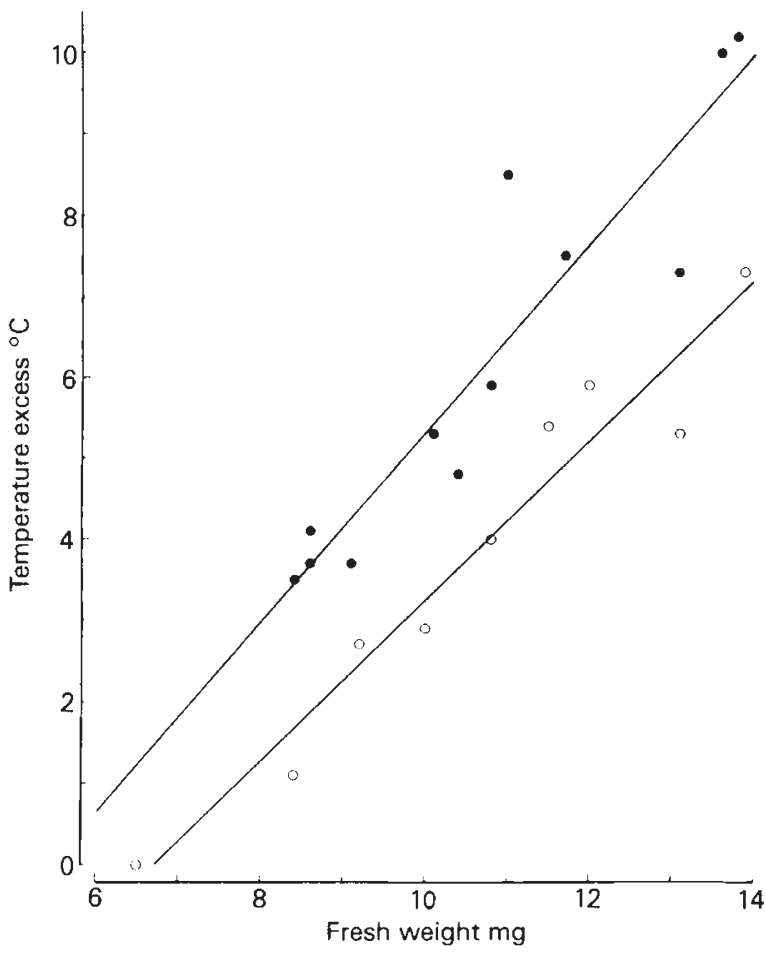

Figure 2 The temperature excess over ambient air reached under bright illumination by non-melanic $(O)$ and melanic (-) Adalia bipunctata plotted against fresh weight. The fitted regression lines are given by: non-melanics, $\hat{\mathrm{Y}}=-6.61+0.986 \mathrm{X} ;$ melanics, $\hat{\mathrm{Y}}=-6.33+1 \cdot 164 \mathrm{X}$.

morph class shows a significant increase in $T$. ex with weight (non-melanics, $F=119.0$; melanics, $F=64.5$ with $P<0.001$ for each value). The regression lines do not differ significantly in slope $(t=1.01, \mathrm{df}=17)$ but they do differ in position $(t=3.47, \mathrm{df}=18, P<0.01$; tests described in Zar, 1974, pp. 228-230). Thus examination of Fig. 2 confirms that melanics exhibit a larger $T$. ex than non-melanics. The test beetles covered the range of size-variation in the total sample. For A. bipunctata of mean fresh weight $(10.7 \mathrm{mg})$ the regression equations indicate that the expected $T$.ex for melanics is $2.1{ }^{\circ} \mathrm{C}$ higher than that for nonmelanics. The $T$. ex for males is smaller than that for females (Table $2 ; U=83 \cdot 5, P=0 \cdot 049$ ). This relationship is associated with a lower fresh weight of the males $(t=2 \cdot 36, P<0.05)$ and is a result of the sexual dimorphism found in natural populations (Brakefield, 1984a). The four specimens of sexpustulata show no indication of behaving differently to the quadrimaculata (Table 2) although since the former have, on average, a larger total area of red marks, larger sample sizes might detect a small difference between these melanic morphs.
We also recorded temperature changes for two specimens of the coccinellid Exochomus quadripustulatus (L.) which is a "good" Müllerian mimic of the quadrimaculata melanic morph of $A$. bipunctata. These gave temperature excesses which are close to the fitted regression line for melanic $A$. bipunctata shown in Fig. $2\left(T\right.$. ex $=7 \cdot 3^{\circ} \mathrm{C}$ for each, with fresh weights of $9 \cdot 8$ and $10.9 \mathrm{mg}$ ). The initial rates of temperature change $\mathrm{K}$ were also similar $\left(0 \cdot 211\right.$ and $0 \cdot 248^{\circ} \mathrm{C} / \mathrm{s}$ respectively, cf. Table 2$)$.

The half-time of temperature change for nonmelanic $A$. bipunctata increases with fresh weight $(b=+3 \cdot 65, F=20 \cdot 4, P<0 \cdot 01)$. There is no corresponding relationship for melanics $(b=+2 \cdot 37$, $F=4.91, P>0.1)$ and the initial rate of temperature change $K$ is independent of weight for both non-melanics and melanics $(b=+0 \cdot 0012$, $F=0.23$ and $b=+0.0067, F=1.78$ respectively, with $P>0.1$ for each). Comparisons between the morph classes show that although there is no significant difference in mean $T \cdot \frac{1}{2}(U=78 \cdot 5, P \approx 0 \cdot 09$ with means: non-mel. $=39 \cdot 2 \mathrm{~s}$, mel. $=33 \cdot 1 \mathrm{~s}$ ), the difference in $T$. ex means that melanics exhibit higher values of $\mathrm{K}(U=108 \cdot 0, P<0.001$ with means: non-mel. $=0 \cdot 137^{\circ} \mathrm{C} / \mathrm{s}$, mel. $=0 \cdot 202^{\circ} \mathrm{C} / \mathrm{s}$ ). The melanics clearly gain and lose heat more rapidly than non-melanics.

\section{DISCUSSION}

Our results show that under illumination which is similar to bright sunlight melanic $A$. bipunctata achieve higher body temperatures and exhibit more rapid temperature changes than nonmelanics. The effect of colour is substantial for the freshly-killed beetles used in our experiments. Thus the expected mean difference in equilibrium body temperature is $2 \cdot 1{ }^{\circ} \mathrm{C}$ and the initial rate of temperature change is nearly 50 per cent faster in melanics. This difference in thermal properties is associated with a difference in cuticular reflectance. The melanics absorb some 91-97 per cent of incoming radiation, while the red non-melanics absorb only 78-85 per cent. These figures are comparable to the extreme values found by Willmer and Unwin (1981) in a survey of over fifty temperate species of insect including several Coleoptera.

The demonstration of consistent differences in thermal properties between the morph classes of A. bipunctata provides a sound basis for the theory of thermal melanism (Lusis, 1961; Benham et al., 1974; Muggleton et al., 1975). These differences are likely to result in differential activity; for example, in cooler ambient temperatures in spring, 
melanics in direct insolation will tend to become active faster and exhibit more intense activity than non-melanics. Thus, this study lends support to the hypothesis that the earlier reproduction by, and mating advantage to, melanics in spring posthibernation populations in The Netherlands are consequences of thermal melanism (Brakefield, $1984 b, c)$. A similar argument applies to the negative correlations found in some study areas between sunshine level and melanic frequency (Muggleton et al., 1975; Brakefield, 1984a) although direct evidence for the causal nature of such a statistical relationship must be obtained (Brakefield, 1984b).

The observed positive relationship between temperature excess and weight in $A$. bipunctata suggests that at very high temperatures smaller beetles may be at an advantage since the larger ones may be in danger of overheating during prolonged exposure to direct insolation. In particular the larger melanics (mostly females), which in our tests show temperature excesses of up to $10^{\circ} \mathrm{C}$ or above (fig. 2), may experience heat-stress. There is evidence that in The Netherlands an increase in melanic frequency between the post-hibernation adult populations and their offspring emerging in early or mid-summer which is associated with the mating advantage is counter-balanced in some populations by a decline in frequency during midor late summer prior to hibernation (Brakefield, $1984 d)$. A higher risk of overheating provides a possible explanation of the selection against melanics. An examination of seasonal changes in size relationships with respect to morph and sex would be valuable. In general, studies of the activity of individual $A$. bipunctata in natural microhabitats are now required to enable a proper assessment of the contribution of thermal melanism to the dynamics of the polymorphism to be made (see Brakefield, 1984b).

Our temperature records suggest that selection on $A$. bipunctata in conditions of low sunshine may favour melanism, an increase in size or some combination of these. Thus different responses may occur to similar climates encountered in different geographical regions. The Netherlands is characterised by a region of low, and one of high melanic frequency, with a zone of transition in between where changes in frequency can be steep (Brakefield, 1984a). A negative correlation is found between melanic frequency and level of sunshine in this area. There was no difference in dry weight between $A$. bipunctata from a population of intermediate melanic frequency and two of high frequency (Brakefield, 1984a). Unfortunately no populations from within the region of low melanic frequency were examined for size and therefore the data do not fully exclude the possibility of a response in size as well as in melanism to changes in level of sunshine in The Netherlands. Further data from this area and comparable data from populations in other areas with extremes of melanic frequency and/or of level of sunshine (see Muggleton, 1978) would be interesting. In relation to such differences in climate, it is critical to determine whether they actually prevail during periods of the life cycle of $A$. bipunctata when thermal melanism is likely to influence the polymorphism, as for example during adult reproduction (Brakefield, $1984 b, c$ ).

The temperature excesses for A. bipunctata are in general considerably larger than those for insects of similar weight found by Willmer and Unwin (1981). Similarly, the rates of initial temperature change when calculated in the same way are low for A. bipunctata in comparison to the range of values obtained by Willmer and Unwin for insects of similar reflectance. These differences are probably largely due to the compact, half-spherical shape of coccinellids. This insect form was not represented in Willmer and Unwin's survey.

The relative contribution of colour and size to the thermal budgets of insects has been a subject of some controversy (see reviews by Casey, 1981; Willmer, 1982a). The consensus suggests that size is substantially more important than colour, though comparative studies have usually involved different species. The investigation of colour polymorphisms such as that in A. bipunctata enables the effects of colour and size to be more rigorously separated since other variables such as shape and physiology are standardised. Some other studies of colour variation within species of insects have provided evidence that darker phenotypes show higher temperature excesses and more rapid temperature changes than paler ones (refs. in Brakefield, 1984b; Willmer, 1982a). In addition the present study shows that while for A. bipunctata of low weight, melanics gain a temperature excess which is at least double that of non-melanics, the difference for the heaviest beetles is only about 40 per cent (fig. 2). Thus the relative contribution of colour to heating and cooling apparently decreases with size, although the difference between the morph classes remains consistently large. Thermal melanism in A. bipunctata is likely to have complex consequences for the adult biology and the dynamics of the polymorphism. The analysis of some of these has begun (Brakefield, 1984b,c) but others are probably still to be determined. 
Acknowledgements We thank Clive Bromhall for the loan of the digital thermocouple meter and Barbara Vermeulen for typing the manuscript. We are also grateful to an anonymous referee for his comments.

\section{REFERENCES}

BENHAM, B. R., LONSDALE, D. AND MUGGLETON, J. 1974. Is polymorphism in two-spot ladybird an example of nonindustrial melanism? Nature (London), 249, 179-180.

BISHOP, J. A., COOK, L. M. AND MUGGlETON, J. 1978. The response of two species of moths to industrialization in northwest England. I. Polymorphisms for melanism. Phil. Trans. Roy. Soc. Lond. B., 281, 489-515.

BRAKEFIELD, P. M. $1984 a$. Ecological studies on the polymorphic ladybird Adalia bipunctata in The Netherlands. I. Population biology and geographical variation of melanism. J. Anim. Ecol., 53, 761-774.

BRAKEFIELD, P. M. 1984b. Ecological studies on the polymorphic ladybird Adalia bipunctata in The Netherlands. II. Population dynamics, differential timing of reproduction and thermal melanism. J. Anim. Ecol., 53, 775-790.

BRAKEFIELD, P. M. 1984 c. Selection along clines in the ladybird Adalia bipunctata in The Netherlands: A general mating advantage to melanics and its consequences. Heredity, 53, 37-49.

BRAKEFIELD, P. M. 1984d. Differential winter mortality and seasonal selection in the polymorphic ladybird Adalia bipunctata (L.) in The Netherlands. Biol. J. Linn. Soc., 23 (in press).

CASEY, T. M. 1981. Behavioural mechanisms of thermoregulation. In Heinrich B. (ed.) Insect Thermoregulation, WileyInterscience, New York, pp. 73-114.

C.REED, E. R. 1966. Geographic variation in the two-spot ladybird in England and Wales. Heredity, 21, 57-72.

CREED, E. R. $197 \mathrm{I}$ a. Melanism in the two-spot ladybird, Adalia bipunctata in Great Britain. In Creed, E. R. (ed.) Ecological Genetics and Evolution, Blackwell Scientific Publications, Oxford, pp. 134-151.

CREEO, E. R. 1971 b. Industrial melanism and smoke abatement. Evolution, 25, 290-293.
CREED, E. R. 1974. Two spot ladybirds as indicators of intense local air pollution. Nature (London), 249, 390-392.

DIGBY, P. S. B. 1955. Factors affecting the temperature excess of insects in sunshine. J. Exp. Biol., 32, 279-298.

FRAZER, J. F. D. AND ROTHSCHILD, M. 1960. Defense mechanisms in warningly-coloured moths and other insects. Proc. 11th Int. Cong. Ent., 3, 249-256.

LEES, D. R., CREED, E. R. AND DUCKETT, J. G. 1973. Atmospheric pollution and industrial melanism. Heredity, 30, $227-232$.

LUS, J. J. 1928. On the inheritance of colour and pattern in lady beetles Adalia bipunctata $\mathrm{L}$. and Adalia decempunctata L. Izv. Byuro. Genet. Leningrad, 6, 89-163.

LUS, J. J. 1932. An analysis of the dominance phenomenon in the inheritance of the elytra and pronotum colour in Adalia bipunctata. Trudy Lab. Genet., 9, 135-162.

LUSIS, J. J. 1961. On the biological meaning of colour polymorphism of lady beetle Adalia bipunctata L. Latv. Ent., 4, 3-29.

MUGGLETON, J. 1978. Selection against the melanic morphs of Adalia bipunctata (two-spot ladybird): a review and some new data. Heredity, 40, 269-280.

MUGGLETON, J., LONSDALE, D. AND BENHAM, B. R. 1975. Melanism in Adalia bipunctata L. (Col., Coccinellidae) and its relationship to atmospheric pollution. J. appl. Ecol., $12,451-464$.

PASTEEls, J. M., DEROE, C., TURSCH, B., BRAEKMAN, J. C., DAlOzE, D. AND HOOTEle, C. 1973. Distribution et activités des alcaloïdes défensifs des Coccinellidae. $J$. Insect Physiol., 19, 1771-1784.

UNWIN, D. M. 1980. Microclimate Measurement for Ecologists. Academic Press, London.

WILlMER, P. G. 1982a. Microclimate and the environmental physiology of insects. Adv. Insect Physiol., 16, 1-57.

WILLMER, P. G. 1982b. Hygrothermal determinants of insect activity patterns: the Diptera of water-lily leaves. Ecol. Ent., 7, 221-231.

WILlMER, P. G. 1983. Thermal constraints on activity patterns in nectar-feeding insects. Ecol. Ent., 8, 455-469.

WILLMER, P. G. AND UNWIN, D. M. 1981. Field analyses of insect heat budgets: Reflectance, size and heating rates. Oecologia (Berl.), 50, 250-255.

ZAR, J. H. 1974. Biostatistical Analysis. Prentice-Hall, N. J. 